Pacific Journal of Mathematics

ZETA FUNCTIONS ON THE REAL GENERAL LINEAR GROUP 


\section{ZETA FUNCTIONS ON THE REAL GENERAL LINEAR GROUP}

\section{GARTH WARNER}

In this paper, the zeta functions on the real general linear group, formed relative to arbitrary positive definite zonal spherical functions, are defined and studied. The main result asserts that such functions satisfy a functional equation and can be meromorphically continued to the whole complex plane.

1. Introduction. Let $\boldsymbol{R}$ denote the field of real numbers. Let $M=M(n, \boldsymbol{R})$ denote the $n^{2}$-dimensional vector space over $\boldsymbol{R}$ comprised of all $n \times n$ matrices with real coefficients, $G=G L(n, \boldsymbol{R})$ the subset of $M$ consisting of those elements with nonzero determinant. As is known, $G$ is a locally compact unimodular group whose Haar measure $d_{G}(x)(x \in G)$ is given, up to a constant factor, by

$$
d_{G}(x)=|x|^{-n} d_{M}(x) \quad(|x|=|\operatorname{det}(x)|),
$$

$d_{M}(x)$ being normalized Lebesgue measure on $M$. Let

$$
K=\{x \in G: x \cdot t=1\},
$$

the ' $t$ ' denoting transpose-then the orthogonal group $K$ is a maximal compact subgroup of $G$.

Given $x, y$ in $M$, let us agree to write $(x, y)$ for $\operatorname{tr}\left(x^{*} y\right)$. Viewing $M$ as an (additive) locally compact abelian group, the Fourier transform $\hat{f}$ of any element $f$ belonging to the Schwartz space $\mathscr{C}(M)$ of $M$ (i.e., the $C^{\infty}$, rapidly decreasing functions on $M$ ) is defined by the rule:

$$
\hat{f}(x)=\int_{M} f(y) e^{2 \pi \sqrt{-1}(x, y)} d_{M}(y) \quad(x \in M) .
$$

With these conventions, one then has the relation

$$
\widehat{\hat{f}}(x)=f(-x) \quad(x \in M)
$$

valid for all $f$ in $\mathscr{C}(M)$.

By $\mathscr{J}(M)$ we shall understand the subspace of $\mathscr{C}(M)$ made up of those $f$ which are biinvariant under $K$, i.e., which have the property that

$$
f\left(k_{1} x k_{2}\right)=f(x) \quad(x \in G)
$$

for all $k_{1}, k_{2} \in K$. This being so, fix an $f$ in $\mathscr{J}(M)$. Then, relative to a given positive definite zonal spherical function $\Phi$ on $G$, the zeta 
function $\zeta(f, \Phi, s)$ of $f$ with respect to $\Phi$ is that function of the complex variable $s$ defined by:

$$
\zeta(f, \Phi, s)=\int_{G} f(x) \Phi(x)|x|^{s} d_{G}(x) .
$$

It is elementary that the integral on the right converges absolutely and defines a holomorphic function of $s$ whenever $\operatorname{Re}(s)>n-1$. The problem which we shall consider in this note is that of effecting a meromorphic continuation of $\zeta(f, \Phi, s)$ to the whole complex plane. In so doing we shall derive a functional equation relating $\zeta(f, \Phi, s)$ and $\zeta(\hat{f}, \bar{\Phi}, n-s)(\bar{\Phi}$ the complex conjugate of $\Phi)$. [In passing, note that the integral defining $\zeta(\hat{f}, \bar{\Phi}, n-s)$ converges for all $s$ such that $\operatorname{Re}(s)<1$.]

Precisely stated, the theorem that will be established can be formulated as follows. Let $s_{1}, \cdots, s_{n}$ be the parameters of our given positive definite zonal spherical function $\Phi$ (see $\S 2$ below) and put

$$
\gamma\left(s_{1}, \cdots, s_{n}\right)=\pi^{-\operatorname{Re}\left(\Sigma_{i} s_{i}\right)+2^{-1}\left(n^{2}-n\right)} .
$$

For complex $z$, we shall agree to write

$$
\Gamma_{R}(z)=\pi^{1 / 2-z} \frac{\Gamma\left(\frac{z}{2}\right)}{\Gamma\left(\frac{1-z}{2}\right)},
$$

$\Gamma$ the classical Gamma function.

THEOREM. Let $f \in \mathscr{J}(M)$-then the zeta function $\zeta(f, \Phi, s)$ of $f$ with respect to $\Phi$, initially defined by the rule

$$
\zeta(f, \Phi, s)=\int_{G} f(x) \Phi(x)|x|^{s} d_{G}(x)
$$

for $\operatorname{Re}(s)>n-1$, can be meromorphically continued to the whole $s$ plane and, for $\operatorname{Re}(s) \leqq 0$, the functional equation

$$
\zeta(f, \Phi, s)=\left\{\gamma\left(s_{1}, \cdots, s_{n}\right) \prod_{i=1}^{n} \Gamma_{R}\left(s-s_{i}\right)\right\} \zeta(\hat{f}, \bar{\Phi}, n-s)
$$

obtains.

The proof of this result is similar in spirit to the analogous statement proved by Tate in his thesis for the case $n=1$ (cf. Lang [4, Chapter 7]). The main technical tool is Lemma 2 in $\$ 2$ below. To actually carry out the meromorphic continuation for all $f$ belonging 
to $\mathscr{I}(M)$ (and not just those having compact support), we shall use an argument due to Stein [7]; see $\S 3$ infra.

As for related results and possible extensions of the theory, we point out that there is no difficulty treating $M(n, \boldsymbol{C})$ and $G L(n, \boldsymbol{C})(\boldsymbol{C}$ the field of complex numbers); in fact Stein [7] has already considered this case when $\Phi \equiv 1$. On the other hand, Gelbart [2] in his thesis treated $M(n, \boldsymbol{R})$ and $G L(n, \boldsymbol{R})$ but considered there only the special situation when $\Phi \equiv 1$. For a historical survey of the subject in general, the reader may find the paper of Andrianov [1] to be of value.

Finally, for details on zonal spherical functions and related questions, we refer the reader to Helgason [3, Chapter 10].

2. The Main Lemma. We shall retain the notations introduced in $\S 1$; in particular, the symbols $G, K$, and $M$ have the same meaning as there. Let

$$
B=\left\{b=\left(b_{i j}\right) \in G: b_{i j}=0(i>j) \text { and } b_{i i}>0\right\} .
$$

Then one has the 'Iwasawa decomposition' $G=K B=B K$ with $K \cap$ $B=\{1\}$. Relative to this decomposition of $G$, it will be convenient to normalize the Haar measure $d_{G}(x)$ on $G$ as follows. First normalize the Haar measure $d_{K}(k)$ on the compact group $K$ by the condition

$$
\operatorname{vol}(K)=\int_{K} d_{K}(k)=1 .
$$

Second normalize the right and left invariant Haar measures $d_{B}^{r}(b)$ and $d_{B}^{l}(b)$, respectively, on $B$ by the conditions

$$
\begin{aligned}
& d_{B}^{r}(b)=2^{n} \prod_{i=1}^{n} b_{i i}^{-i} \prod_{i=1}^{n} d b_{i i} \prod_{i<j} d b_{i j}, \\
& d_{B}^{l}(b)=\prod_{i=1}^{n} b_{i i}^{(2 i-n-1)} d_{B}^{r}(b),
\end{aligned}
$$

$d b_{i i}, d b_{i j}$ being normalized Lebesque measure on the ambient 1-dimensional space over $\boldsymbol{R}$. Finally normalize the Haar measure $d_{G}(x)$ on $G$ via the stipulation

$$
d_{G}(x)=d_{K}(k) d_{B}^{r}(b)=d_{B}^{l}(b) d_{K}(k) .
$$

Let $\Phi$ be a positive definite zonal spherical function on $G$-then $\Phi$ possesses the following properties:

(1) $\Phi(1)=1, \Phi\left(k_{1} x k_{2}\right)=\Phi(x)\left(k_{1}, k_{2} \in K ; x \in G\right)$;

(2) $\Phi\left(x^{-1}\right)=\overline{\Phi(x)}(x \in G)$;

(3) $|\Phi(x)| \leqq 1 \quad(x \in G)$;

(4) $\Phi(x) \Phi(y)=\int_{K} \Phi(x k y) d_{K}(k)(x, y \in G)$. 
In addition there exists a continuous homomorphism

$$
\chi: B \rightarrow C^{*}
$$

of $B$ into the multiplicative group of complex numbers such that

$$
\Phi(x)=\int_{K} \chi(x k) d_{K}(k) \quad(x \in G)
$$

where $\chi$ has been extended from $B$ to $G$ by the prescription

$$
\chi(x)=\chi(k b)=\chi(b) \quad(x \in G, x=k b(k \in K, b \in B)) .
$$

Because $\chi$ has the form

$$
b \mapsto \prod_{i=1}^{n}\left|b_{i i}\right|^{-\left(s_{i}-(i-1)\right)} \quad\left(b=\left(b_{i j}\right) \in B\right)
$$

for certain complex parameters $s_{1}, \cdots, s_{n}$, we shall sometimes write $\chi_{\left(s_{i}\right)}$ for $\chi$ and then denote the associated positive definite zonal spherical function $\Phi$ by $\Phi_{\left(s_{i}\right)}$ so that

$$
\Phi_{\left(s_{i}\right)}(x)=\int_{K} \chi_{\left(s_{i}\right)}(x k) d_{K}(k) \quad(x \in G) .
$$

Now fix once and for all a positive definite zonal spherical function $\Phi$ on $G$. Given $f \in \mathscr{J}(M)$, define a function $\zeta(f, \Phi, s)$ of the complex variable $s$ by:

$$
\zeta(f, \Phi, s)=\int_{G} f(x) \Phi(x)|x|^{s} d_{G}(x) .
$$

Lemma 1. The integral defining $\zeta(f, \Phi, s)(f \in \mathscr{I}(M))$ is absolutely convergent for $\operatorname{Re}(s)>n-1$.

Proof. Since $|\Phi(x)| \leqq 1$ for all $x \in G$, it is clear that one need only verify that the integral

$$
\int_{G}|f(x)| \cdot|x|^{s} d_{G}(x) \quad(f \in \mathscr{J}(M))
$$

is convergent for $\operatorname{Re}(s)>n-1$. This, however, is well-known and easy to prove (see, e.g. Gelbart [2, p. 36]).

Let $I_{c}^{\infty}(G)$ denote the subspace of $C_{c}^{\infty}(G)$ consisting of those functions which are biinvariant under $K$-then it is clear that $I_{c}^{\infty}(G) \subset$ $\mathscr{J}(M)$. We come now to the main technical lemma for the present investigation.

Lemma 2. If $f, g \in I_{c}^{\infty}(G)$ and if $\operatorname{Re}(s)<1$, then

$$
\zeta(f, \Phi, s) \zeta(\hat{g}, \bar{\Phi}, n-s)=\zeta(\hat{f}, \bar{\Phi}, n-s) \zeta(g, \Phi, s) \text {. }
$$


Proof. To begin with, observe that since $f, g \in I_{c}^{\infty}(G)$, the zeta functions $\zeta(f, \Phi, s), \zeta(g, \Phi, s)$ are actually well-defined for all values of $s$. On the other hand, the Fourier transforms $\hat{f}, \hat{g}$ evidently lie in $\mathscr{J}(M)$ and so the zeta functions $\zeta(\hat{f}, \bar{\Phi}, n-s), \zeta(\hat{g}, \bar{\Phi}, n-s)$ are well-defined whenever $\operatorname{Re}(s)<1$ (cf. Lemma 1). Therefore, all the zeta functions appearing in the statement of our lemma make sense for $\operatorname{Re}(s)<1$. To establish the asserted equality, note first that

$$
\begin{aligned}
\zeta(f, \Phi, s) & =\int_{G} f(x) \Phi(x)|x|^{s} d_{G}(x) \\
& =\int_{G} f(x)\left(\int_{K} \chi(x k) d_{K}(k)\right)|x|^{s} d_{G}(x) \\
& =\int_{G} f(x) \chi(x)|x|^{s} d_{G}(x) \\
& =\int_{B} \int_{K} f(k b) \chi(k b)|k b|^{s} d_{K}(k) d_{B}^{r}(b) \\
& =\int_{B} f(b) \chi(b)|b|^{s} d_{B}^{r}(b) .
\end{aligned}
$$

In a similar way we find that

$$
\begin{aligned}
\zeta(\widehat{g}, \bar{\Phi}, n-s) & =\int_{G} \hat{g}(x) \bar{\Phi}(x)|x|^{n-s} d_{G}(x) \\
& =\int_{G} \hat{g}(x)\left(\int_{K} \chi\left(x^{-1} k\right) d_{K}(k)\right)|x|^{n-s} d_{G}(x) \\
& =\int_{G} \hat{g}(x) \chi\left(x^{-1}\right)|x|^{n-s} d_{G}(x) \\
& =\int_{K} \int_{B} \hat{g}(b k) \chi\left(k^{-1} b^{-1}\right)|b k|^{n-s} d_{B}^{l}(b) d_{K}(k) \\
& =\int_{B} \hat{g}(b) \chi\left(b^{-1}\right)|b|^{n-s} d_{B}^{l}(b) .
\end{aligned}
$$

Hence:

$$
\begin{aligned}
\zeta(f, & \Phi, s) \zeta(\hat{g}, \bar{\Phi}, n-s) \\
& =\int_{B} \int_{B} f\left(b^{\prime}\right) \hat{g}\left(b^{\prime \prime}\right) \chi\left(b^{\prime}\right) \chi\left(b^{\prime \prime}\right)^{-1}\left|b^{\prime}\right|^{s}\left|b^{\prime \prime}\right|^{n-s} d_{B}^{r}\left(b^{\prime}\right) d_{B}^{l}\left(b^{\prime \prime}\right) \\
& =\int_{B} f\left(b^{\prime}\right) \chi\left(b^{\prime}\right)\left|b^{\prime}\right|^{s}\left(\int_{B} \widehat{g}\left(b^{\prime} b^{\prime \prime}\right) \chi\left(b^{\prime} b^{\prime \prime}\right)^{-1}\left|b^{\prime} b^{\prime \prime}\right|^{n-s} d_{B}^{l}\left(b^{\prime \prime}\right)\right) d_{B}^{r}\left(b^{\prime}\right) \\
& =\int_{B}\left(\int_{B} f\left(b^{\prime}\right) \hat{g}\left(b^{\prime} b^{\prime \prime}\right)\left|b^{\prime}\right|^{n} d_{B}^{r}\left(b^{\prime}\right)\right) \chi\left(b^{\prime \prime}\right)^{-1}\left|b^{\prime \prime}\right|^{n-s} d_{B}^{l}\left(b^{\prime \prime}\right)
\end{aligned}
$$

Let us consider the inner integral in the last equality. Thus, we can write

$$
\begin{aligned}
\int_{B} f\left(b^{\prime}\right) \hat{g}\left(b^{\prime} b^{\prime \prime}\right)\left|b^{\prime}\right|{ }^{n} d_{B}^{r}\left(b^{\prime}\right) \\
\quad=\int_{B} \int_{K} f\left(k b^{\prime}\right) \hat{g}\left(k b^{\prime} b^{\prime \prime}\right)\left|k b^{\prime}\right|^{n} d_{K}(k) d_{B}^{r}(b)
\end{aligned}
$$




$$
\begin{aligned}
& =\int_{G} f(x) \hat{g}\left(x b^{\prime \prime}\right)|x|^{n} d_{G}(x) \\
& =\int_{G} \hat{f}\left(x b^{\prime \prime}\right) g(x)|x|^{n} d_{G}(x) \\
& =\int_{B} \hat{f}\left(b^{\prime} b^{\prime \prime}\right) g\left(b^{\prime}\right)\left|b^{\prime}\right|^{n} d_{B}^{r}\left(b^{\prime}\right) .
\end{aligned}
$$

It therefore follows that

$$
\begin{aligned}
\zeta(f, \Phi, s) \zeta(\widehat{g}, \bar{\Phi}, n-s) \\
=\int_{B}\left(\int_{B} \hat{f}\left(b^{\prime} b^{\prime \prime}\right) g\left(b^{\prime}\right)\left|b^{\prime}\right|{ }^{n} d_{B}^{r}\left(b^{\prime}\right)\right) \chi\left(b^{\prime \prime}\right)^{-1}\left|b^{\prime \prime}\right|^{n-s} d_{B}^{l}\left(b^{\prime \prime}\right) \\
=\int_{B} g\left(b^{\prime}\right)\left|b^{\prime}\right|^{n}\left(\int_{B} \hat{f}\left(b^{\prime} b^{\prime \prime}\right) \chi\left(b^{\prime \prime}\right)^{-1}\left|b^{\prime \prime}\right|^{n-s} d_{B}^{l}\left(b^{\prime \prime}\right)\right) d_{B}^{r}\left(b^{\prime}\right) .
\end{aligned}
$$

Now make the change of variable $b^{\prime \prime} \mapsto\left(b^{\prime}\right)^{-1} b^{\prime \prime}$ in the last relation. This gives:

$$
\begin{aligned}
\zeta(f, \Phi, s) \zeta(\hat{g}, \bar{\Phi}, n-s) \\
\quad=\left(\int_{B} g\left(b^{\prime}\right) \chi\left(b^{\prime}\right)\left|b^{\prime}\right|{ }^{s} d_{B}^{r}\left(b^{\prime}\right)\right) \cdot\left(\left.\int_{B} \hat{f}\left(b^{\prime \prime}\right) \chi\left(b^{\prime \prime}\right)^{-1}\left|b^{\prime \prime}\right|\right|^{n-s} d_{B}^{l}\left(b^{\prime \prime}\right)\right) \\
\quad=\zeta(g, \Phi, s) \zeta(\hat{f}, \bar{\Phi}, n-s),
\end{aligned}
$$

which is the desired relation.

CoRollary. There exists a scalar c(s), depending only on $s$, such that

$$
\zeta(f, \Phi, s)=c(s) \zeta(\hat{f}, \bar{\Phi}, n-s)
$$

for all $f \in I_{c}^{\infty}(G)$ whenever $\operatorname{Re}(s)<1$.

In order to determine $c(s)$ explicitly, it first will be necessary to extend Lemma 2 to a different class of functions and then to summarize the results of some well-known computations.

Let $\Delta$ denote the differential operator on $M$ associated with the polynomial [ $\operatorname{det}(x)]^{2}(x \in M)$ : If $x=\left(x_{i j}\right) \in M$, then

$$
\Delta=\left[\operatorname{det}\left(\partial / \partial x_{i j}\right)\right]^{2} \text {. }
$$

Let $\Delta^{N}$ denote the $N$ th iterate of $\Delta(N=1,2, \cdots)$-then it follows from the "operational calculus" for Fourier transforms that

$$
\left(\Delta^{N} f\right)^{\Lambda}(x)=(2 \pi \sqrt{-1})^{2 n N}|x|^{2 N} \hat{f}(x) \quad(x \in M)
$$

for all $f \in \mathscr{C}(M)$.

By $[n / 2]$ we shall understand, as usual, the greatest integer in $n / 2$. 
LEMmA 3. There exists a scalar $C(s)$, depending only on $s$, such that

$$
\zeta\left(\Delta^{[n / 2]} f, \Phi, s\right)=C(s) \zeta\left(\left(\Delta^{[n / 2]} f\right)^{4}, \bar{\Phi}, n-s\right)
$$

for all $f \in \mathscr{I}(M)$ whenever $n-1<\operatorname{Re}(s)<2[n / 2]+1$.

Proof. Let $f \in \mathscr{I}(M)$-then, since $\Delta^{[n / 2]} f \in \mathscr{I}(M)$, the integral defining $\zeta\left(\Delta^{[n / 2]} f, \Phi, s\right)$ converges for $\operatorname{Re}(s)>n-1$ (cf. Lemma 1). On the other hand,

$$
\left(4^{[n / 2]} f\right)^{A}(x)=(2 \pi \sqrt{-1})^{2 n[n / 2]}|x|^{2[n / 2]} \hat{f}(x) \quad(x \in M)
$$

and so the integral defining $\zeta\left(\left(\Delta^{[n / 2]} f\right)^{4}, \bar{\Phi}, n-s\right)$ converges for $\operatorname{Re}(s)<$ $2[n / 2]+1$. Consequently both sides of the asserted equality in our lemma make sense in the strip $n-1<\operatorname{Re}(s)<2[n / 2]+1$. This being so, the argument used in the proof of Lemma 2 implies that

$$
\left.\zeta\left(\Delta^{[n / 2]} f, \Phi, s\right) \zeta\left(\left(\Delta^{[n / 2]} g\right)^{\Lambda}, \bar{\Phi}, n-s\right)=\zeta\left(\left(\Delta^{[n / 2}\right] f\right)^{\Lambda}, \bar{\Phi}, n-s\right) \zeta\left(\Delta^{[n / 2]} g, \Phi, s\right)
$$

for all $f, g \in \mathscr{J}(M)$ whenever $n-1<\operatorname{Re}(s)<2[n / 2]+1$. The lemma now follows at once.

Let us now recall some computations which go back to Maass [5, p. 3] and Selberg [6, p. 59]. Write

$$
\boldsymbol{e}(x)=e^{-\pi(x, x)} \quad(x \in M) .
$$

Then $\boldsymbol{e}$ lies in $\mathscr{J}(M)$ and, moreover, $\hat{\boldsymbol{e}}=\boldsymbol{e}$. Consider the integral

$$
\int_{G}\left(\Delta^{[n / 2]} e\right)(x)|x|^{s} d_{G}(x)
$$

which defines $\zeta\left(\Delta^{[n / 2]} e, \Phi, s\right)$ : This integral converges absolutely in the region $\operatorname{Re}(s)>n-1$, and, moreover, the holomorphic function $\zeta\left(\Delta^{[n / 2]} e, \Phi, s\right)$ so defined can be meromorphically continued to the whole $s$-plane and is equal to

$$
(2 \pi \sqrt{-1})^{2 n[n / 2]} \pi^{2^{-1}\left(\Sigma_{i^{s}} i^{-n(2[n / 2]+s))}\right.} \prod_{i=1}^{n} \prod_{k=1}^{[n / 2]}\left(\frac{1+s_{i}-s}{2}+k-1\right) \Gamma\left(\frac{s-s_{i}}{2}\right),
$$

$\Gamma$ the classical Gamma function. [Here $s_{1}, \cdots, s_{n}$ are the parameters of $\Phi$.] On the other hand, consider the integral

$$
\int_{G}\left(4^{[n / 2]} e\right)^{A}(x) \overline{\Phi(x)}|x|^{8} d_{G}(x)
$$

which defines $\zeta\left(\left(\Delta^{[n / 2]} e\right)^{\Lambda}, \bar{\Phi}, s\right)$ : This integral converges absolutely in the region $\operatorname{Re}(s)>n-1$, and, moreover, the holomorphic function $\zeta\left(\left(\Delta^{[n / 2]} e\right)^{4}, \bar{\Phi}, s\right)$ so defined can be meromorphically continued to the whole $s$-plane and is equal to 


$$
(2 \pi \sqrt{-1})^{2 n[n / 2]} \pi^{2^{-1}\left(\Sigma_{i} \bar{s}_{i-n(2[n / 2]+s))}\right.} \prod_{i=1}^{n} \prod_{k=1}^{[n / 2]}\left(\frac{s-\bar{s}_{i}}{2}+k-1\right) \Gamma\left(\frac{s-\bar{s}_{i}}{2}\right),
$$

$\bar{s}_{1}, \cdots, \bar{s}_{n}$ being the parameters of $\bar{\Phi}$.

Bearing in mind the above relations, it is then a simple matter to compute the scalar $C(s)$ which appears in Lemma $3(n-1<\operatorname{Re}(s)<$ $2[n / 2]+1)$. Thus we must have

$$
\zeta\left(\Delta^{[n / 2]} e, \Phi, s\right)=C(s) \zeta\left(\left(\Delta^{[n / 2]} e\right)^{4}, \bar{\Phi}, n-s\right)
$$

for all $s$ in the strip $n-1<\operatorname{Re}(s)<2[n / 2]+1$. This being so, if we now take into account the fact that

$$
\bar{s}_{i}=n-1-s_{\sigma(i)} \quad(1 \leqq i \leqq n)
$$

for some permutation $\sigma$ of the set $(1, \cdots, n$ ) (which follows from the relation $\left.\bar{\Phi}(x)=\Phi\left(x^{-1}\right)(x \in G)\right)$ and then utilize the explicit formulae given above, we immediately deduce that

$$
C(s)=\gamma\left(s_{1}, \cdots, s_{n}\right) \prod_{i=1}^{n} \Gamma_{R}\left(s-s_{i}\right)(n-1<\operatorname{Re}(s)<2[n / 2]+1)
$$

where, for complex $z$,

$$
\Gamma_{R}(z)=\pi^{1 / 2-z} \frac{\Gamma\left(\frac{z}{2}\right)}{\Gamma\left(\frac{1-z}{2}\right)} .
$$

Here, for simplicity, we have written

$$
\gamma\left(s_{1}, \cdots, s_{n}\right)=\pi^{-\operatorname{Re}\left(\Sigma_{i} s_{i}\right)+2^{-1}\left(n^{2}-n\right)} .
$$

We shall now identify the scalar $c(s)$ which appears in the Corollary to Lemma 2 with the scalar $C(s)$ above.

Lemma 4. Let $f \in I_{c}^{\infty}(G)$-then the zeta function $\zeta(f, \Phi, s)$ of $f$ with respect to $\Phi$ has the value

$$
\left\{\gamma\left(s_{1}, \cdots, s_{n}\right) \prod_{i=1}^{n} \Gamma_{R}\left(s-s_{i}\right)\right\} \zeta(\hat{f}, \bar{\Phi}, n-s)
$$

for all s such that $\operatorname{Re}(s)<1$.

Proof. Suppose first that $g$ is an arbitrary element in $\mathscr{I}(M)$ then, in view of what has been said above, the function $\zeta\left(\Delta^{[n / 2]} g, \Phi, s\right)$ has a meromorphic continuation to the whole $s$-plane give by the functional equation 


$$
\zeta\left(\Delta^{[n / 2]} g, \Phi, s\right)=\left\{\gamma\left(s_{1}, \cdots, s_{n}\right) \prod_{i=1}^{n} \Gamma_{R}\left(s-s_{i}\right)\right\} \zeta\left(\left(\Delta^{[n / 2]} g\right)^{4}, \bar{\Phi}, n-s\right) .
$$

Specialize now and choose a $g \in I_{c}^{\infty}(G)$ having the property that $\zeta\left(\Delta^{[n / 2]} g, \Phi, s\right)$ is not identically zero-then, thanks to Lemma 2 , we have

$$
\begin{aligned}
\zeta(f, \Phi, s) \zeta\left(\left(\Delta^{[n / 2]} g\right)^{4}, \bar{\Phi}, n-s\right)= & \zeta(\hat{f}, \bar{\Phi}, n-s) \zeta\left(\left(\Delta^{[n / 2]} g\right), \Phi, s\right) \\
= & \left\{\gamma\left(s_{1}, \cdots, s_{n}\right) \prod_{i=1}^{n} \Gamma_{R}\left(s-s_{i}\right)\right\} \\
& \times \zeta(\widehat{f}, \bar{\Phi}, n-s) \zeta\left(\left(\Delta^{[n / 2]} g\right)^{4}, \bar{\Phi}, n-s\right)
\end{aligned}
$$

whenever $\operatorname{Re}(s)<1$. From these considerations, the lemma then follows at once.

3. The meromorphic continuation. Let us agree to retain the assumptions and notations which were introduced in the preceding section. As has been mentioned at the beginning, the objective of the present note is to establish the following theorem.

THEOREM. Let $f \in \mathscr{J}(M)$-then the function

$$
\zeta(f, \Phi, s)=\int_{G} f(x) \Phi(x)|x|^{s} d_{G}(x),
$$

initially defined for $\operatorname{Re}(s)>n-1$, can be meromorphically continued to the whole s-plane, and for $\operatorname{Re}(s) \leqq 0$, the functional equation

$$
\zeta(f, \Phi, s)=\left\{\gamma\left(s_{1}, \cdots, s_{n}\right) \prod_{i=1}^{n} \Gamma_{R}\left(s-s_{i}\right)\right\} \zeta(\hat{f}, \bar{\Phi}, n-s)
$$

obtains.

The proof of this theorem is contained in the discussion infra. As will become apparent, there is no loss of generality in assuming that the Haar measure $d_{G}(x)$ on $G$ has been so chosen that

$$
d_{G}(x)=|x|^{-n} d_{M}(x),
$$

$d_{M}(x)$ being normalized Lebesgue measure on $M$. (Recall that in $\S 2$ we used a slightly different convention.)

To begin with, suppose that $f$ actually lies in $I_{c}^{\infty}(G)$-then the validity of our theorem in this case is ensured by Lemma 4. Now suppose only that $f$ belongs to $I_{c}^{\infty}(M)$ (the space of $K$-biinvariant compactly supported $C^{\infty}$ functions on $M$ ). In this situation one may employ an argument due to Stein [7, p. 488-490] which, in brief, goes as follows. First one easily shows that, for some sufficiently large positive integer $N$, the function $f_{N}$ defined by the rule 


$$
f_{N}(x)=|x|^{N} f(x) \quad(x \in M)
$$

has the property that there exists a family $\varphi_{\varepsilon}, \varphi_{\varepsilon} \in I_{c}^{\infty}(G)(\varepsilon>0)$, such that:

(1) $\varphi_{\varepsilon} \rightarrow f_{N}$ in $L^{1}(M)$ as $\varepsilon \rightarrow 0$;

(2) $\hat{\varphi}_{\varepsilon} \rightarrow \hat{f}_{N}$ in $L^{1}(M)$ as $\varepsilon \rightarrow 0$.

This being so, put

$$
I_{\varepsilon}(s)=\frac{1}{\Omega(s)} \int_{G} \varphi_{\varepsilon}(x) \Phi(x)|x|^{s} d_{G}(x)
$$

where

$$
Q(s)=\gamma\left(s_{1}, \cdots, s_{n}\right) \prod_{i=1}^{n} \Gamma_{R}\left(s-s_{i}\right) .
$$

Now assume that $s$ lies in the strip $0 \leqq R e(s) \leqq n$. In view of standard properties of the Gamma function, $1 / \Omega(s)$ is meromorphic in this strip and is at most of polynomial growth there. Fix a rational function $Q$, with roots outside the strip, so that

$$
\left|\frac{1}{\Omega(s)} \cdot \frac{1}{Q(s)}\right| \leqq 1 \text { and }\left|\frac{1}{Q(s)}\right| \leqq 1
$$

in the strip. Then it is clear that $I_{\varepsilon}(s) / Q(s)$ is bounded in the strip for each $\varepsilon$. Moreover, we have the estimates

$$
\begin{aligned}
& \left|\frac{I_{\varepsilon}(s)}{Q(s)}\right|_{\operatorname{Re}(s)=n} \leqq \int_{M}\left|\varphi_{\varepsilon}(x)\right| d_{M}(x)=\left\|\varphi_{\varepsilon}\right\|_{1}, \\
& \left|\frac{I_{\varepsilon}(s)}{Q(s)}\right|_{\operatorname{Re}(s)=0} \leqq \int_{M}\left|\hat{\varphi}_{\varepsilon}(x)\right| d_{M}(x)=\left\|\hat{\varphi}_{\varepsilon}\right\|_{1},
\end{aligned}
$$

whence, by the maximum principle,

$$
\left|\frac{I_{\varepsilon}(s)}{Q(s)}\right| \leqq \operatorname{Max}\left[\left\|\varphi_{\varepsilon}\right\|_{1},\left\|\hat{\varphi}_{\varepsilon}\right\|_{1}\right], \quad 0 \leqq \operatorname{Re}(s) \leqq n .
$$

In a similar way, one finds that

$$
\left|\frac{I_{\varepsilon_{1}}(s)}{Q(s)}-\frac{I_{\varepsilon_{2}}(s)}{Q(s)}\right| \leqq \operatorname{Max}\left[\left\|\varphi_{\varepsilon_{1}}-\varphi_{\varepsilon_{2}}\right\|_{1},\left\|\widehat{\varphi}_{\varepsilon_{1}}-\hat{\varphi}_{\varepsilon_{2}}\right\|_{1}\right], \quad 0 \leqq \operatorname{Re}(s) \leqq n .
$$

Thus $I_{\varepsilon}(s) / Q(s)$ and so also $I_{\varepsilon}(s)$ converges uniformly as $\varepsilon \rightarrow 0$ on those bounded subsets of the strip which avoid the finitely many poles of $1 / \Omega(s)$. But

$$
\lim _{\varepsilon \rightarrow 0} I_{\varepsilon}(s)=\frac{1}{\Omega(s)} \int_{G} f_{N}(x) \Phi(x)|x|^{s} d_{G}(x) \text { for } \operatorname{Re}(s)=n,
$$

and 


$$
\lim _{s \rightarrow 0} I_{s}(s)=\int_{G} \hat{f}_{N}(x) \bar{\Phi}(x)|x|^{n-s} d_{G}(x) \quad \text { for } \quad \operatorname{Re}(s)=0,
$$

whence the function

$$
I(s)=\frac{1}{\Omega(s)} \int_{G} f_{N}(x) \Phi(x)|x|^{s} d_{G}(x),
$$

initially defined for $\operatorname{Re}(s) \geqq n$, has a meromorphic continuation into the strip $0 \leqq \operatorname{Re}(s) \leqq n$ and its value for $\operatorname{Re}(s)=0$ is given by $\int_{G} \hat{f}_{N}(x) \bar{\Phi}(x)|x|^{n-s} d_{G}(x)$; from the latter integral, the meromorphic continuation of $I(s)$ into the remainder $(\operatorname{Re}(\mathrm{s})<0)$ of the $s$-plane is immediate. It remains to pass from $f_{N}$ to $f$ itself-this, however, is merely an obvious formal computation (cf. Stein [7, p. 490]).

We now know that our theorem is valid for all $f$ lying in $I_{c}^{\infty}(M)$. To extend the result to $\mathscr{I}(M)$, one may argue exactly as we did above in the case of $I_{c}^{\infty}(M)$. Here, though, the position is somewhat simpler since $I_{c}^{\infty}(M)$ is dense in $\mathscr{F}(M)(\mathscr{F}(M)$ being equipped with its usual Frechet space topology); in particular, one does not have to employ the artifice of first working with $f_{\Lambda}$ and then passing to $f$ itself $(f \in \mathscr{Y}(M)) \cdots$.

The proof of the theorem is therefore complete.

\section{REFERENCES}

1. A. N. Andrianov, Zeta functions of simple algebras with non-abelian characters, Russ. Math. Surveys, 23 (1968), 1-65.

2. S. S. Gelbart, Fourier analysis on matrix space, Memoirs Amer. Math. Soc., No. 108, Providence, Rhode Island, 1971.

3. S. Helgason, Differential Geometry and Symmetric Spaces, Academic Press, New York, 1962.

4. S. Lang, Algebraic Numbers, Addison-Wesley, Reading, Mass., 1964.

5. H. Maass, Die bestimmung der Dirichletreihen mit Grössencharakteren zu den modulformen n-ten grades, J. Indian Math. Soc., 19 (1955), 1-24.

6. A. Selberg, Harmonic analysis and discontinuous groups in weakly symmetric Riemannian spaces with applications to Dirichlet series, J. Indian Math. Soc., 20 (1956), 47-87.

7. E. M. Stein, Analysis in matrix spaces and some new representations of $S L(n, C)$, Ann. of Math., 86 (1967), 461-490.

Received February 11, 1972.

UNIVERSITY OF WASHINGTON 



\section{PACIFIC JOURNAL OF MATHEMATICS}

\section{EDITORS}

\author{
H. SAMELson \\ Stanford University \\ Stanford, California 94305 \\ C. R. HоввY \\ University of Washington \\ Seattle, Washington 98105
}

J. DugundJI

Department of Mathematics

University of Southern California

Los Angeles, California 90007

RICHARD ARENS

University of California

Los Angeles, California 90024

\section{ASSOCIATE EDITORS}
E. F. BeCKENBACH
B. H. NEUMANN
F. WOLF
K. YoshidA

\section{SUPPORTING INSTITUTIONS}

UNIVERSITY OF BRITISH COLUMBIA

CALIFORNIA INSTITUTE OF TECHNOLOGY

UNIVERSITY OF CALIFORNIA

MONTANA STATE UNIVERSITY

UNIVERSITY OF NEVADA

NEW MEXICO STATE UNIVERSITY

OREGON STATE UNIVERSITY

UNIVERSITY OF OREGON

OSAKA UNIVERSITY

\author{
UNIVERSITY OF SOUTHERN CALIFORNIA \\ STANFORD UNIVERSITY \\ UNIVERSITY OF TOKYO \\ UNIVERSITY OF UTAH \\ WASHINGTON STATE UNIVERSITY \\ UNIVERSITY OF WASHINGTON

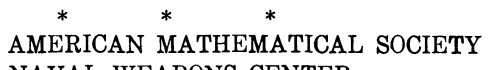 \\ NAVAL WEAPONS CENTER
}

The Supporting Institutions listed above contribute to the cost of publication of this Journal, but they are not owners or publishers and have no responsibility for its content or policies.

Mathematical papers intended for publication in the Pacific Journal of Mathematics should be in typed form or offset-reproduced, (not dittoed), double spaced with large margins. Underline Greek letters in red, German in green, and script in blue. The first paragraph or two must be capable of being used separately as a synopsis of the entire paper. The editorial "we" must not be used in the synopsis, and items of the bibliography should not be cited there unless absolutely necessary, in which case they must be identified by author and Journal, rather than by item number. Manuscripts, in duplicate if possible, may be sent to any one of the four editors. Please classify according to the scheme of Math. Rev. Index to Vol. 39. All other communications to the editors should be addressed to the managing editor, Richard Arens, University of California, Los Angeles, California, 90024.

50 reprints are provided free for each article; additional copies may be obtained at cost in multiples of 50 .

The Pacific Journal of Mathematics is issued monthly as of January 1966. Regular subscription rate: $\$ 48.00$ a year (6 Vols., 12 issues). Special rate: $\$ 24.00$ a year to individual members of supporting institutions.

Subscriptions, orders for back numbers, and changes of address should be sent to Pacific Journal of Mathematics, 103 Highland Boulevard, Berkeley, California, 94708.

PUBLISHED BY PACIFIC JOURNAL OF MATHEMATICS, A NON-PROFIT CORPORATION

Printed at Kokusai Bunken Insatsusha (International Academic Printing Co., Ltd.), 270, 3-chome Totsuka-cho, Shinjuku-ku, Tokyo 160, Japan. 


\section{Pacific Journal of Mathematics}

\section{Vol. 45, No. $2 \quad$ October, 1973}

Kenneth Paul Baclawski and Kenneth Kapp, Induced topologies for quasigroups and loops ............................................. 393

D. G. Bourgin, Fixed point and $\min -\max$ theorems $\ldots \ldots \ldots \ldots \ldots \ldots \ldots$

J. L. Brenner, Zolotarev's theorem on the Legendre symbol ............... 413

Jospeh Atkins Childress, Jr., Restricting isotopies of spheres .............. 415

John Edward Coury, Some results on lacunary Walsh series ................ 419

James B. Derr and N. P. Mukherjee, Generalized Sylow tower groups. II . . . . . . 427

Paul Frazier Duvall, Jr., Peter Fletcher and Robert Allen McCoy, Isotopy Galois

spaces .......................................... 435

Mary Rodriguez Embry, Strictly cyclic operator algebras on a Banach space ... 443

Abi (Abiadbollah) Fattahi, On generalizations of Sylow tower groups ......... 453

Burton I. Fein and Murray M. Schacher, Maximal subfields of tensor products . . 479

Ervin Fried and J. Sichler, Homomorphisms of commutative rings with unit

element .......................................... 485

Kenneth R. Goodearl, Essential products of nonsingular rings ............. 493

George Grätzer, Bjarni Jónsson and H. Lakser, The amalgamation property in

equational classes of modular lattices ...........................

507

$\mathrm{H}$. Groemer, On some mean values associated with a randomly selected simplex

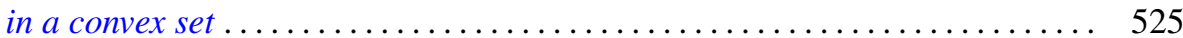

Marcel Herzog, Central 2-Sylow intersections .................... 535

Joel Saul Hillel, On the number of type-k translation-invariant groups ........ 539

Ronald Brian Kirk, A note on the Mackey topology for $\left(C^{b}(X)^{*}, C^{b}(X)\right) \ldots \ldots .543$

J. W. Lea, The peripherality of irreducible elements of lattice.............. 555

John Stewart Locker, Self-adjointness for multi-point differential operators ..... 561

Robert Patrick Martineau, Splitting of group representations ............... 571

Robert Massagli, On a new radical in a topological ring ................. 577

James Murdoch McPherson, Wild arcs in three-space. I. Families of Fox-Artin

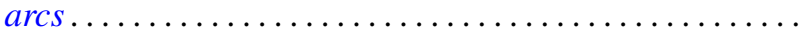

585

James Murdoch McPherson, Wild arcs in three-space. III. An invariant of

oriented local type for exceptional arcs . . . . . . . . . . . . ............ 599

Fred Richman, The constructive theory of countable abelian p-groups ........ 621

Edward Barry Saff and J. L. Walsh, On the convergence of rational functions

which interpolate in the roots of unity ..................

Harold Eugene Schlais, Non-aposyndesis and non-hereditary

decomposability..................................... 643

Mark Lawrence Teply, A class of divisible modules................... 653

Edward Joseph Tully, Jr., H-commutative semigroups in which each

homomorphism is uniquely determined by its kernel ................. 669

Garth William Warner, Jr., Zeta functions on the real general linear group ...... 681

Keith Yale, Cocyles with range $\{ \pm 1\} \ldots \ldots \ldots \ldots \ldots \ldots \ldots \ldots \ldots \ldots \ldots \ldots \ldots . \ldots \ldots$

Chi-Lin Yen, On the rest points of a nonlinear nonexpansive semigroup ........ 699 